1 Enhanced bacterial decomposition with increasing addition

2 of autochthonous to allochthonous carbon without any

3 effect on bacterial community composition

4 K. Attermeyer ${ }^{1}$, T. Hornick ${ }^{1}$, Z. E. Kayler ${ }^{2}$, A. Bahr ${ }^{3}$, E. Zwirnmann ${ }^{4}$, H.-P.

5 Grossart $^{1,5}$, and K. Premke ${ }^{2,4}$

$6 \quad[1]\{$ Leibniz Institute of Freshwater Ecology and Inland Fisheries (IGB) Berlin, Experimental

7 Limnology, 16775 Stechlin, Germany

8 [2]\{Leibniz Centre for Agricultural Landscape Research (ZALF), 15374 Müncheberg,

9 Germany

10 [3]\{UFZ-Helmholtz Centre for Environmental Research - Department of Isotope 11 Biogeochemistry, 04318 Leipzig, Germany\}

$12[4]\{$ Leibniz Institute of Freshwater Ecology and Inland Fisheries (IGB), 12587 Berlin, 13 Germany\}

$14[5]\{$ Potsdam University, Institute for Biochemistry and Biology, 14469 Potsdam, Germany $\}$

15 Correspondence to: K. Attermeyer (attermeyer@igb-berlin.de $)$ 


\section{Appendix A: Methods}

\section{A1 Chemical analysis}

DOC concentrations ( $\mathrm{mg} \mathrm{C} \mathrm{L}^{-1}$ ) were determined with an organic $\mathrm{C}$ analyzer (Shimadzu, TOC-V CPH, Duisburg, Germany). After filtration through a $0.2 \mu \mathrm{m}$ pre-rinsed cellulose nitrate filter, DOC was analyzed as non-purgeable $\mathrm{C}$ after acidification with $1 \%(\mathrm{v} / \mathrm{v}) 2 \mathrm{~mol} \mathrm{~L}^{-}$ ${ }^{1} \mathrm{HCl}$. The carbon dioxide generated by catalytic high-temperature oxidation $\left(850^{\circ} \mathrm{C}\right)$ was measured online by infrared absorption. The quality of DOC was characterized by size exclusion chromatography with online carbon and nitrogen detection (Liquid Chromatography - Organic Carbon Detection- Organic Nitrogen Detection; LC-OCD-OND; Huber et al., 2011). Briefly, the chromatographable DOC portion of the filtered samples passes through a size-exclusion column packed with resin (Toyopearl HW 50S, volume of $250 \times 20 \mathrm{~mm})$. Phosphate buffer $\left(0.029 \mathrm{~mol} \mathrm{~L}^{-1}, \mathrm{pH} 6.5\right)$ was used as eluent at a flow rate of $1.1 \mathrm{ml} \mathrm{min}^{-1}$. The first detector measured the absorbance at $254 \mathrm{~nm}$. DOC was detected with infrared (IR) absorbance of $\mathrm{CO}_{2}$ after ultraviolet (UV) oxidation of DOC at $185 \mathrm{~nm}$ in a cylindrical UV thin-film reactor (Graentzel-reactor). Fractions were identified by using fulvic and humic acid standards from the International Humic Substances Society and analyzed with a suitable software program (FIFFIKUS; DOC-Labor Huber, Karlsruhe, Germany). DOC was summarized in three fractions: high molecular weight substances (HMWS, e.g. polysaccharides), humic or humic-like substances (HS) including buildings blocks and low molecular weight substances (LMWS), which include both low molecular weight acids and low molecular weight neutral substances. HMWS and HS are known to be recalcitrant to microbial degradation (Hessen and Tranvik, 1998) and LMWS are more labile due to their low molecular weight (Saunders, 1976). The ratio between the spectral absorption coefficient (SAC in $\mathrm{m}^{-1}$, at $254 \mathrm{~nm}$ ) and the organic carbon of the humic fraction (in $\mathrm{mg} \mathrm{C} \mathrm{L}^{-1}$ ) was calculated as aromaticity (so called SAC/OC: specific UV-absorption of the HS peak, $\mathrm{L} \mathrm{mg}^{-1}$ $\left.\mathrm{m}^{-1}\right)$.

\section{A2 PLFA analysis and determination of stable carbon isotope ratios of PLFA}

Total lipids were extracted from $200 \mathrm{ml}$ water samples filtered over a $0.2 \mu \mathrm{m}$ polyvinyl fluoride filter using a modified Bligh and Dyer method as described by Frostegård et al. (1991) and changed after Steger et al. (2011). After lipid fractionation on silicic acid columns (BondElut ${ }^{\circledR}$ LRC-Si, Agilent Technologies, Santa Clara, USA), the phospholipids in the polar fraction were dried under a gentle stream of nitrogen and converted to fatty acid methyl esters 
1 (FAME) by a mild alkaline methanolysis (Guckert et al. 1985). Before analysis, the 2 completely dried FAME fraction was dissolved in $\mathrm{n}$-hexane containing $20.06 \mathrm{ng} \mu \mathrm{L}^{-1}$ of the 3 fatty acid 21:0 as an internal standard. For identification and quantification of the FAMEs, a 4 gas chromatograph coupled to a mass spectrometer (Agilent, Palo Alto, USA) was used as described in Bastida et al. (2011). One $\mu 1$ aliquots were injected with either splitless mode or at different split ratios of up to 1:50. FAMEs were identified by comparison of fatty acid mass spectra of standards (bacterial acid methyl ester mix, Supelco, Munich, Germany) and to the NIST MS database. The concentration of each FAME was quantified relative to the internal standard. The fatty acid nomenclature was used according to Bastida et al. (2011).

\section{References}

Frostegård, Å, Tunlid, A., and Bååth, E., Microbial biomass measured as total lipid phosphate in soils of different organic content, J. Microbiol. Met., 14, 151-163, 1991.

Guckert, J. B., Antworth, C. P., Nichols, P. D., and White, D. C.: Phospholipid, ester-linked fatty acid profiles as reproducible assays for changes in prokaryotic community structure of estuarine sediments, FEMS Microbiol. Ecol., 31, 147-158, 1985.

Hessen, D. O., and Tranvik, L. J., (eds.): Aquatic humic substances: ecology and biogeochemistry, Springer-Verlag, Berlin, Heidelberg, Germany, 1998.

Huber, S. A., Balz, A., Abert, A., and Pronk,W.: Characterisation of aquatic humic and nonhumic matter with size-exclusion chromatography - organic carbon detection - organic nitrogen detection (LC-OCD-OND), Water Res., 45, 879-885, 2011.

Saunders, G.: Decomposition in fresh water, p. 341- 374. In J. Anderson and A. Macfadyen [eds.], The role of terrestrial and aquatic organisms in decomposition processes. Blackwell, 1976.

Steger, K., Premke, G., Gudasz, C., Sundh, I., and Tranvik, L. J.: Microbial biomass and community composition in boreal lake sediments, Limnol. Oceanogr., 56, 725-733, 2011. 


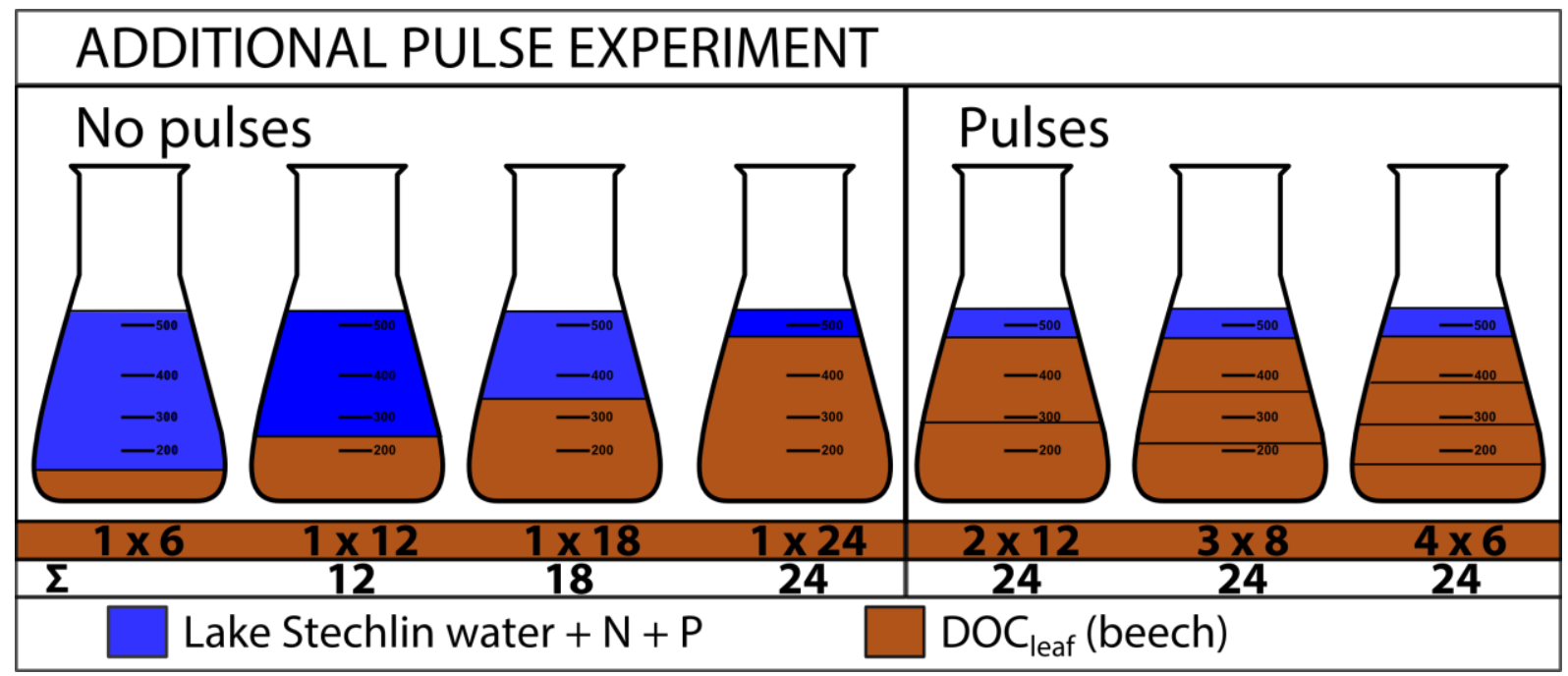

Figure B1: Experimental set-up of the additional pulse experiment showing the two parts with and without pulses.

\section{Experimental set-up}

We performed an additional pulse experiment to test whether pulsing in DOC addition has an influence on bacterial DOC consumption. We used lake water and the natural bacterial community plus nutrients (oligotrophic Lake Stechlin in northern Germany; for more details see Allgaier and Grossart 2006) and a single DOC source (beech $\mathrm{DOC}_{\text {leaf }}$ ). The $\mathrm{DOC}_{\text {leaf }}$ was added at the beginning of the experiment without any pulses, but at increasing DOC concentrations. DOC concentrations increased by $6 \mathrm{mg} \mathrm{C} \mathrm{L}^{-1}$ from 6 to $24 \mathrm{mg} \mathrm{C} \mathrm{L}^{-1}$ in $250 \mathrm{ml}$ Erlenmeyer flasks (see figure1). Additionally, we performed three incubations with the same total DOC concentrations but with an increasing number of pulses (see figure 1). All incubations were done in triplicates for 12 days under the same conditions as in the main experiment. We measured DOC concentrations (procedure described in the methods section of the manuscript) and calculated DOC consumption after 12 days.

\section{Results}

19 The DOC consumption increased with increasing DOC concentrations (from $45 \%$ in treatment $1 \times 6$ to $58 \%$ in $1 \times 12,64 \%$ in $1 \times 18$, and $67 \%$ in treatment $1 \times 24$, respectively) but were the same $(67 \%$ in treatment $1 \times 24$ and $69 \%$ in treatment $4 \times 6)$ for the $24 \mathrm{mg} \mathrm{C} \mathrm{L}^{-1}$ treatment without pulses and in all other pulsed incubations with the same total DOC 
1 concentrations (Fig. A1). The treatments without pulses were significantly different (Kruskal-

2 Wallis; $\mathrm{df}=3$ and $\mathrm{p}=0.016$ ). In contrast, treatments with varying DOC pulses were not

3 significantly different (Kruskal-Wallis; $\mathrm{df}=3$ and $\mathrm{p}=0.059$ ). This confirms that the pulses

4 had no influence on bacterial DOC consumption, whereas differences in DOC concentrations

5 significantly affected it.

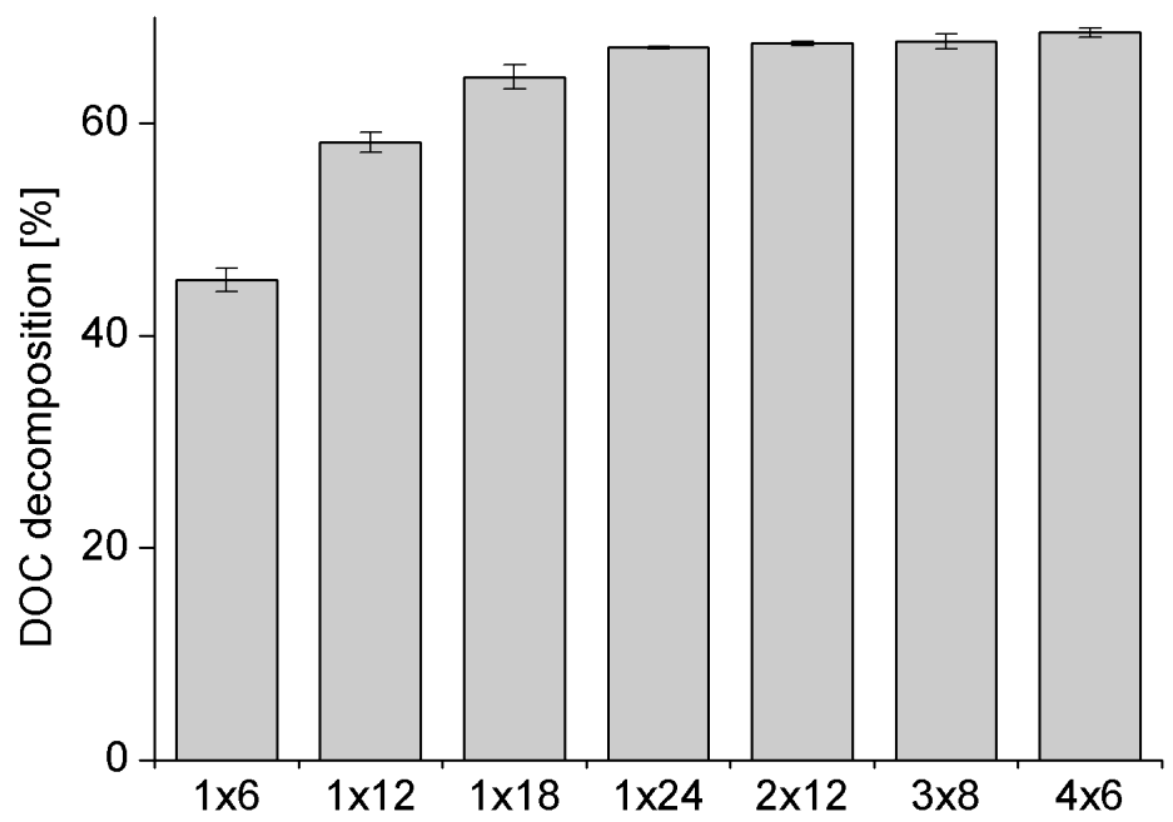

6

7 Figure B2. DOC consumed (mean \pm standard deviation; in \%) after 12 days in the four 8 treatments with increasing DOC $(1 \times 6,1 \times 12,1 \times 18,1 \times 24)$ and in the three treatments with 9 pulsed DOC input $(2 \times 12,3 \times 8,4 \times 6)$.

10

\section{References}

12 Allgaier M., Grossart H.-P.: Seasonal dynamics and phylogenetic diversity of free-living and 13 particle-associated bacterial communities in four lakes in northeastern Germany, Aquat. 14 Microb. Ecol., 45, 115-128, 2006. 
1 Appendix C: Liquid Chromatography with Organic Carbon Detection (LC-OCD)

2 of illuminated and non-illuminated $\mathrm{DOC}_{\text {leat }}$ without microorganisms.

3 Experimental set-up

4 We incubated beech leachate $\mathrm{DOC}\left(\mathrm{DOC}_{\text {leaf }}\right)$ in sterile conditions to test whether the presence 5 of light in our incubation has an influence on DOC quality. Therefore, we set up $250 \mathrm{ml}$ 6 Erlenmeyer flasks with beech $\mathrm{DOC}_{\text {leaf }}$ at $7 \mathrm{mg} \mathrm{C} \mathrm{L}^{-1}$ diluted with double distilled water. We 7 incubated three Erlenmeyer flasks in light comparable to the incubation conditions of the 8 main experiment and three Erlenmeyer flasks in complete darkness. After one week we froze 9 the samples until further chemical analysis. The samples were analysed with the Liquid 10 Chromatography - Organic Carbon Detection - Organic Nitrogen Detection (LC-OCD-OND) 11 as described in the method section of the manuscript.

\section{Results}

13 We detected no significant differences between the light and dark treatments (Fig. B1). Upon 14 illumination, there was a slight decrease in HS and an accompanied increase in LMWS. In 15 general, however, the quality revealed by LC-OCD did not change by illumination when 16 comparing the start $\left(t_{0}\right)$ with the end of the incubation (Mann-Whitney $U ; p>0.05$ for $t_{0}$ vs. $t_{7}$ non-light and for $t_{0} v s . t_{7}$ light) and in the light and dark treatment at the end of the experiment 18 (Kruskal-Wallis; $\mathrm{p}>0.05$ for dark vs. light). 


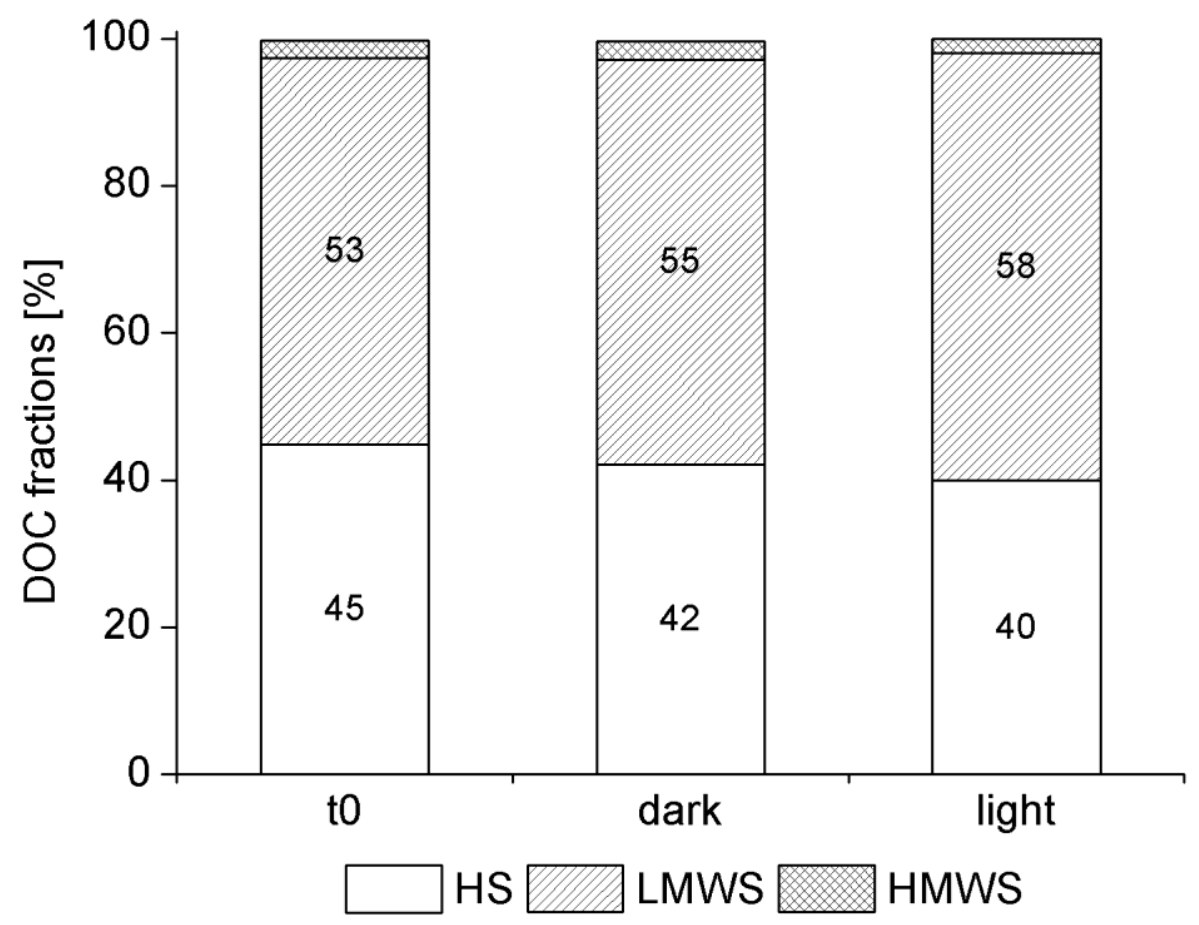

1

2 Figure C1. Percentage of measured DOC fractions at the start $\left(\mathrm{t}_{0}\right)$ and end $\left(\mathrm{t}_{7}\right)$ of the 3 incubation in both dark and light treatment. According to Huber et al. (2011) we claimed the 4 fractions HS which represent humic like substances and building blocks, LMWS consist of 5 low molecular weight substances and HMWS depict high molecular weight substances. 